\title{
Gazpacho consumption is associated with lower blood pressure and reduced hypertension in a high cardiovascular risk cohort. Cross-sectional study of the PREDIMED trial
}

\author{
A. Medina-Remón ${ }^{\text {a,b,c,1 }}$, A. Vallverdú-Queralt ${ }^{\text {a,b,c,1 }}$, \\ S. Arranz ${ }^{b, c, d, 1}$, E. Ros ${ }^{b, e, 1}$, M.A. Martínez-Gonzáléz ${ }^{c, f, 1}$, E. Sacanella ${ }^{\text {b,d,1 }}$, \\ M.I. Covas ${ }^{\text {b,g, },}$, D. Corella ${ }^{\text {b'h, }, 1}$, J. Salas-Salvadó ${ }^{b, i, 1}$, E. Gómez-Gracia ${ }^{c, j, 1}$, \\ V. Ruiz-Gutiérrez ${ }^{c, k, 1}$, J. Lapetra ${ }^{b, l, 1}$, \\ M. García-Valdueza ${ }^{\text {b,m,1 }}$, F. Arós ${ }^{\text {n,1 }}$, G.T. Saez ${ }^{c, o, 1}$, L. Serra-Majem ${ }^{\text {c,p, } 1 \text {, }}$ \\ X. Pinto ${ }^{c, q, 1}$, E. Vinyoles ${ }^{b, r, 1}$, R. Estruch ${ }^{b, c, d, 1}$, \\ R.M. Lamuela-Raventos ${ }^{a, b, c, *, 1}$
}

${ }^{a}$ Nutrition and Food Science Department, XaRTA, INSA. Pharmacy School, University of Barcelona, Spain

${ }^{b}$ CIBER:CB06/03 Fisiopatología de la Obesidad y la Nutrición, CIBERobn, Instituto de Salud Carlos III (ISCIII), Spain

${ }^{\mathrm{c}}$ RETICS RD06/0045, ISCIII, Spain

d Department of Internal Medicine, IDIBAPS, Hospital Clinic, University of Barcelona, Spain

e Lipid Clinic, Endocrinology and Nutrition Service, IDIBAPS, Hospital Clinic, Barcelona, Spain

${ }^{f}$ Department of Preventive Medicine and Public Health, School of Medicine, University of Navarra, Pamplona, Spain

${ }^{g}$ Cardiovascular Risk and Nutrition Research Group, IMIM-Institut de Recerca Hospital del Mar, Barcelona, Spain

${ }^{\mathrm{h}}$ Department of Epidemiology, Preventive Medicine and Public Health, School of Medicine, University of Valencia, Valencia, Spain

${ }^{i}$ Human Nutrition Unit, School of Medicine, IISPV, University Rovira i Virgili, Reus, Spain

j Department of Epidemiology, School of Medicine, University of Malaga, Málaga, Spain

${ }^{k}$ Nutrition and Lipids Metabolism, Instituto de la Grasa, Consejo Superior de Investigaciones Cientificas, Sevilla, Spain

'Department of Family Medicine, Primary Care Division of Sevilla, San Pablo Health Center, Sevilla, Spain

$\mathrm{m}$ Institut Universitari d'Investigació en Ciències de la Salut(IUNICS), Palma de Mallorca, Spain

${ }^{\mathrm{n}}$ Clinical Trials Unit, Hospital Universitario de Araba(HUA), Vitoria, Spain

\footnotetext{
Acronyms: BP, blood pressure; $\mathrm{Cl}$, confidence interval; DASH, Dietary Approaches to Stop Hypertension; FFQ, food frequency questionnaire; OR, Odds ratio; PREDIMED, prevention with Mediterranean diet study; SD, standard deviations; TMD, traditional Mediterranean diet.

* Corresponding author. Nutrition and Food Science Department, XaRTA, INSA Pharmacy School, University of Barcelona, Av. Joan XXIII s/n, 08028 Barcelona, Spain. Tel.: +34 934034843; fax: +34 934035931.

E-mail address: lamuela@ub.edu (R.M. Lamuela-Raventos).

${ }^{1}$ On behalf of the PREDIMED Study Investigators.
} 


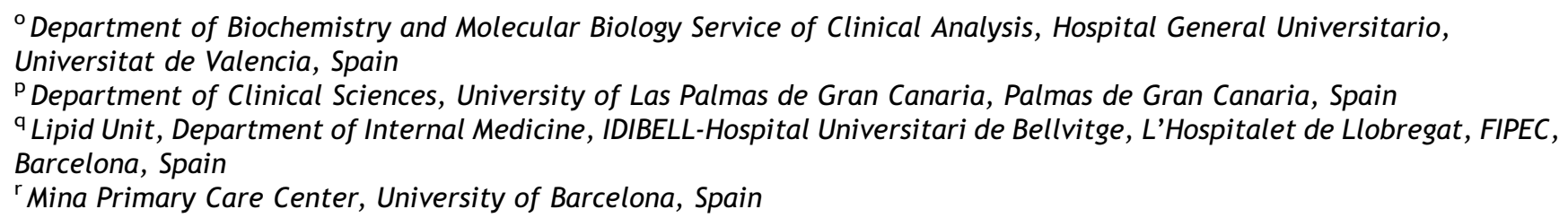

Received 22 January 2012; received in revised form 19 July 2012; accepted 22 July 2012

\section{KEYWORDS \\ Hypertension; \\ Blood pressure; \\ Gazpacho \\ (Mediterranean \\ vegetable soup); \\ PREDIMED study; \\ Polyphenols}

\begin{abstract}
Background and aim: Hypertension is a major public health problem and a leading cause of death and disability in both developed and developing countries, affecting onequarter of the world's adult population. Our aim was to evaluate whether the consumption of gazpacho, a Mediterranean vegetable-based cold soup rich in phytochemicals, is associated with lower blood pressure (BP) and/or reduced prevalence of hypertension in individuals at high cardiovascular risk.

Methods and results: We selected 3995 individuals (58\% women, mean age $67 \mathrm{y}$ ) at high cardiovascular risk ( $81 \%$ hypertensive) recruited into the PREDIMED study. BP, weight, and dietary and physical activity data were collected. In multivariate linear regression analyses, after adjustment, moderate and high gazpacho consumption categories were associated with reduced mean systolic $\mathrm{BP}$ of $-1.9 \mathrm{~mm} \mathrm{Hg}$ [95\% confidence interval $(\mathrm{Cl}):-3.4 ;-0.6]$ and $-2.6 \mathrm{~mm} \mathrm{Hg}(\mathrm{Cl}:-4.2 ;-1.0)$, respectively, and reduced diastolic $\mathrm{BP}$ of $-1.5 \mathrm{~mm} \mathrm{Hg}(\mathrm{Cl}$ : $-2.3 ;-0.6)$ and $-1.9 \mathrm{~mm} \mathrm{Hg}(\mathrm{Cl}:-2.8 ;-1.1)$. By multiple-adjusted logistic regression analysis, gazpacho consumption was associated with a lower prevalence of hypertension, with $\mathrm{OR}=0.85(\mathrm{Cl}: 0.73 ; 0.99)$ for each $250 \mathrm{~g} /$ week increase and $\mathrm{OR}=0.73(\mathrm{Cl}: 0.55 ; 0.98)$ for high gazpacho consumption groups compared to the no-consumption group.

Conclusions: Gazpacho consumption was inversely associated with systolic and diastolic BP and prevalence of hypertension in a cross-sectional Mediterranean population at high cardiovascular risk. The association between gazpacho intake and reduction of BP is probably due to synergy among several bioactive compounds present in the vegetable ingredients used to make the recipe.

(c) 2012 Elsevier B.V. All rights reserved.
\end{abstract}

\section{Introduction}

Hypertension is a leading cause of death and disability in the world [1]. Hypertension results from the interaction between genetic and environmental factors. The principal environmental factors influencing blood pressure (BP) are diet, physical activity and psychosocial factors [2]. Changing dietary habits is considered the principal lifestyle measure in BP control [3] since publication of the landmark DASH (Dietary Approaches to Stop Hypertension) trial [4], and the ensuing DASH-Sodium trail with added salt restriction [5]. More recently, increasing epidemiological and clinical evidence points to the traditional Mediterranean diet (TMD) as an alternative dietary pattern for BP control $[6,7]$. Of note, the healthy diets recommended to subjects with or at risk of hypertension should be low in salt [8], and rich in fruit and vegetables [3].

Epidemiological studies have consistently shown that adherence to the TMD is associated with a reduced risk of overall mortality, cardiovascular disease incidence and mortality, and incidence of major chronic degenerative diseases [9], a protective effect that is attributable in part to the diet's richness in plant-derived foods and the bioactive phytochemicals they contain. The risk of cardiovascular disease has been inversely associated with intake of polyphenol-rich foods, such as fruit and vegetables, tea, cocoa, olive oil and wine $[10,11]$. High consumption of fish and low-fat dairy products may also reduce the risk of hypertension [3,12], whereas high consumption of refined cereals or meat and meat products is associated with greater cardiovascular risk [3,4].

Gazpacho is a traditional Spanish, ready-to-serve cold vegetable soup, containing mainly 5 vegetables, tomato (50\%), cucumber $(15 \%)$, green pepper $(10 \%)$, onion $(3 \%)$ and garlic $(0.8 \%)$, and other minor components such as extra virgin olive oil $(2 \%)$, wine vinegar $(2 \%)$, salt $(0.8 \%)$, sugar $(0.05 \%)$ and water [13]. Gazpacho is presumably beneficial to human health due to its high content in bioactive compounds such as carotenoids (mainly $\beta$-carotene), vitamin $C$ and polyphenols [14]. Raw ingredients in gazpacho exert a potentially valuable functional activity. Adding tomato extract to the diet of moderate hypertensive subjects is associated with a clinically significant reduction of systolic and diastolic BP [15]. Supplementing the diet of patients with uncontrolled hypertension with aged garlic extract also reduces systolic BP [16]. The consumption of olive oil, is 
associated with a wide range of health benefits and could be a contributory factor to the low cardiovascular mortality rates observed in southern European countries in comparison with other Western countries [17].

Since the anti-hypertensive food components of gazpacho may act synergistically to further BP reduction, we undertook a substudy of a large nutritional intervention study, the PREDIMED (prevention with Mediterranean diet) trial [18], in order to assess the cross-sectional association between consumption of gazpacho and both BP and prevalent hypertension in individuals at high cardiovascular risk.

\section{Methods}

\section{Study subjects}

The PREDIMED study is a large, parallel-group, multicenter, randomized, controlled clinical trial of 5-year duration aimed at assessing the effects of the TMD on the primary prevention of cardiovascular disease (www.predimed.org). We undertook a cross-sectional substudy of the baseline data within this larger clinical trial.

The detailed recruitment method and study protocol have been described previously $[7,18]$. For this substudy, we selected 3995 participants recruited in primary health centers affiliated with the Hospital Clinic of Barcelona, University of Valencia, University of Malaga, Department of Family Medicine (Sevilla), and University of Navarra (Pamplona) in Spain. Eligible participants were communitydwelling men aged 55-80 years and women aged $60-80$ years, who were free of cardiovascular disease at baseline and fulfilled at least one of the following two criteria: (1) type-2 diabetes mellitus and/or (2) three or more coronary heart disease $(\mathrm{CHD})$ risk factors: hypertension (systolic BP $\geq 140 \mathrm{~mm} \mathrm{Hg}$ or diastolic BP $\geq 90 \mathrm{~mm} \mathrm{Hg}$ or treatment with antihypertensive medication), dyslipidemia (LDL cholesterol $\geq 160 \mathrm{mg} / \mathrm{dl} ; \mathrm{HDL}$ cholesterol $\leq 40 \mathrm{mg} / \mathrm{dl}$ in men or $\leq 50 \mathrm{mg} / \mathrm{dl}$ in women; or under lipid-lowering therapy), obesity or overweight, smoking or family history of earlyonset CHD [19]. This trial has been registered with the International Standard Randomised Controlled Trial Number (ISRCTN of London, England) 35739639.

\section{Clinical and dietary measurements}

All participants completed at baseline a validated semiquantitative food frequency questionnaire (FFQ) with 137 items, the validated Spanish version, of the Minnesota Leisure Time Physical Activity Questionnaire, a validated 14-point Mediterranean diet score, and a 47-item questionnaire about education, lifestyle, history of illnesses and medication use. These questionnaires took into account all data during one year before entry into the study, date when BP was measured and hypertension status checked [18]. Trained nurses measured height and weight with a wallmounted stadiometer and calibrated scales, respectively. $\mathrm{BP}$ was measured in triplicate with the participant in a seated position after resting quietly for $5 \mathrm{~min}$, using a validated semi-automatic oscillometer (Omron HEM705CP [20]; Hoofddorp, The Netherlands) with a 5-min interval between each measurement. The mean of the three systolic and diastolic BP measurements was calculated. Energy and nutrient intake were derived from Spanish food composition tables.

\section{Statistical analyses}

Analyses were performed using SPSS software v17.0 (Chicago, USA). Baseline characteristics of the participants were expressed as means or percentages and standard deviations (SD). Variables were examined for normality and skewness (Kolmogorov and Levene tests). ANOVA-one factor was used for analysis of continuous variables and $\chi^{2}$-test for categorical variables. Multivariate linear regression models were used to assess the relationship between systolic and diastolic $\mathrm{BP}$ as dependent variables and gazpacho consumption categories as exposure variables (first category: no consumption; second category: moderate consumption, between 1 and $19 \mathrm{~g} /$ day; and third category: high consumption, more than $20 \mathrm{~g}$ /day), as well as a consumption increase of $250 \mathrm{~g} /$ week as an exposure variable, adjusted for potential confounders. Three models were fitted to assess the role of each independent variable (see Table 3). In addition, we carried out a sensitivity analysis of the association of gazpacho consumption with systolic and diastolic BP in a sample restricted to the patients included within the hypertension criterion from the beginning.

Logistic regression models were fitted to assess the relationship between gazpacho consumption as a continuous variable expressed as $250 \mathrm{~g} /$ week or gazpacho consumption categories (no consumption, moderate consumption and high consumption) and hypertension status. OR (Odds ratio) and $95 \% \mathrm{Cl}$ (confidence interval) were calculated. $P$-values $<0.05$ (two-tailed) were considered significant. Diagnostics for the detection of outliers, multicollinearity, homoscedasticity, and the normality and independence of errors were carried out when appropriate.

\section{Results}

We excluded 33 of 3995 eligible participants of the PREDIMED trial for different reasons: not meeting inclusion criteria $(n=15)$, food allergies $(n=5)$ or refusing to participate $(n=13)$. Thus, 3962 participants entered the study, 1626 men [mean age $66.0(6.5) \mathrm{y}$ ] and 2336 women [mean age $67.8(5.6) \mathrm{y}$ ]. Baseline characteristics of the total group by gazpacho consumption category are shown in Table 1. By study design, participants were older than 55 years, mostly overweight [mean body mass index 29.9 (3.6) $\left.\mathrm{kg} / \mathrm{m}^{2}\right]$, and with a sizeable burden of cardiovascular risk factors $(46.4 \%$ diabetics, $81.8 \%$ hypertensive, $71.0 \%$ with dyslipidemia, $14.8 \%$ active smokers and $16.0 \%$ with family history of early-onset CHD).

Most participants adhered to a Mediterranean-style diet, with a relatively high consumption of vegetables, fruit, cereals, olive oil and nuts; a moderate intake of legumes, fish, wine, milk and dairy products; and a lower but still relatively high intake of meat, meat products, pastries and dairy products. Table 2 shows the average food consumption of study participants by gazpacho consumption category. The intake of olive oil, total nuts, fruit, vegetables, total fruit and vegetables, legumes, fish or seafood, milk 
Table 1 Baseline characteristics of study subjects by categories of gazpacho consumption.

\begin{tabular}{|c|c|c|c|c|}
\hline & \multicolumn{4}{|c|}{ Categories of gazpacho consumption (g/day) ${ }^{a}$} \\
\hline & $\begin{array}{l}\text { No consumption }{ }^{\mathrm{b}} \\
(0 \mathrm{~g} / \mathrm{d})\end{array}$ & $\begin{array}{l}\text { Moderate } \\
\text { consumption } \\
(1-19 \mathrm{~g} / \mathrm{d})\end{array}$ & $\begin{array}{l}\text { High consumption } \\
(>20 \mathrm{~g} / \mathrm{d})\end{array}$ & $P^{c}$ \\
\hline No. of subjects & 1878 & 994 & 1090 & \\
\hline Age, $(y)$ mean $\left(S D^{d}\right)$ & $67.56(6.15)$ & $66.75(5.97)$ & $66.91(6.29)$ & 0.001 \\
\hline Women, $n(\%)$ & $1099(58)$ & $609(61)$ & $628(58)$ & 0.21 \\
\hline Weight (Kg), mean (SD) & $75.99(11.45)$ & $76.54(11.79)$ & $77.49(12.26)$ & 0.004 \\
\hline $\mathrm{BMI}^{\mathrm{e}}\left(\mathrm{kg} / \mathrm{m}^{2}\right)$, mean $(\mathrm{SD})$ & $29.83(3.69)$ & $30.09(3.93)$ & $30.19(3.85)$ & 0.032 \\
\hline $\begin{array}{l}\text { Systolic BP }(\mathrm{mm} \mathrm{Hg}) \\
\text { mean }(\mathrm{SD})\end{array}$ & $150(20)$ & $148(20)$ & $147(19)$ & $<0.001$ \\
\hline $\begin{array}{l}\text { Diastolic BP }(\mathrm{mmHg}) \\
\text { mean }(\mathrm{SD})\end{array}$ & $84(11)$ & $82(11)$ & $82(11)$ & $<0.001$ \\
\hline Hypertension, $n(\%)$ & $1546(82)$ & $819(82)$ & $874(80)$ & 0.29 \\
\hline Diabetes, $n(\%)$ & $843(45)$ & $453(46)$ & $542(50)$ & 0.033 \\
\hline Dyslipidemia, n (\%) & $1345(72)$ & $713(72)$ & $756(70)$ & 0.36 \\
\hline Current smoker $n(\%)$ & $261(14)$ & $146(15)$ & $179(16)$ & 0.17 \\
\hline $\begin{array}{l}\text { Family history } \\
\text { of } \mathrm{CHD}^{\mathrm{g}} n(\%)\end{array}$ & $261(14)$ & $166(17)$ & 205 (19) & $<0.001$ \\
\hline \multicolumn{5}{|l|}{ Medication, $n(\%)$} \\
\hline Antihypertensive & $1344(72)$ & $714(73)$ & $802(75)$ & 0.40 \\
\hline $\begin{array}{l}\text { Statins or other } \\
\text { hypolipidemic drugs }\end{array}$ & $872(47)$ & $479(48)$ & $514(47)$ & 0.66 \\
\hline Insulin & 109 (6) & $76(8)$ & $93(9)$ & 0.013 \\
\hline Oral hypoglycemic drugs & $551(29)$ & $306(31)$ & $398(37)$ & $<0.001$ \\
\hline $\begin{array}{l}\text { Aspirin or other } \\
\text { antiplatelet drugs }\end{array}$ & 352 (19) & $222(22)$ & $288(26)$ & $<0.001$ \\
\hline $\begin{array}{l}\text { Vitamins or } \\
\text { supplements, } n \text { (\%) }\end{array}$ & $206(11)$ & $126(13)$ & $133(13)$ & 0.32 \\
\hline \multicolumn{5}{|l|}{ Educational level, $n$ (\%) } \\
\hline Primary school & $1447(77)$ & $695(70)$ & $766(70)$ & $<0.001$ \\
\hline High school & $248(13)$ & $165(17)$ & $193(18)$ & 0.002 \\
\hline University & $127(7)$ & $107(11)$ & 109 (10) & $<0.001$ \\
\hline $\begin{array}{l}\text { Energy expenditure in } \\
\text { physical activity } \\
(\mathrm{kcal} / \mathrm{d}) \text {, mean (SD) }\end{array}$ & $231.40(218.15)$ & $197.39(200.34)$ & $202.02(239.22)$ & $<0.001$ \\
\hline \multicolumn{5}{|c|}{$\begin{array}{l}\text { a Mean (standard deviation). } \\
\text { b Reference category. } \\
\text { c ANOVA-one factor was used for continuous variables and } \chi 2 \text {-test for categorical variables. } \\
\text { d Standard deviation. } \\
\text { e Body mass index (calculated as weight in kilograms divided by height in square meters). } \\
\text { f Blood pressure. } \\
\text { g Coronary heart disease. }\end{array}$} \\
\hline
\end{tabular}

and dairy products, coffee, chocolate, natural orange juice, fiber, cholesterol, sodium, potassium, total polyphenols, and total energy intake increased across gazpacho consumption categories. Conversely, significant decreasing trends existed for the intake of meat or meat products, cereals and wine. Thus, subjects in the highest gazpacho consumption category reported a significantly greater 14point Mediterranean diet score than their counterparts.

In multivariate linear regression analyses (Table 3), a significant inverse association between gazpacho consumption category (g/day) and BP was observed. The two upper categories of gazpacho consumption showed lower levels of systolic and diastolic BP than the category no consumption. Adjusted relative differences in systolic BP were $-1.9 \mathrm{~mm} \mathrm{Hg}$ for moderate consumption and $-2.6 \mathrm{~mm} \mathrm{Hg}$ for high consumption. The relative differences for diastolic BP were $-1.5 \mathrm{~mm} \mathrm{Hg}$ for moderate consumption and $-1.9 \mathrm{~mm} \mathrm{Hg}$ for high consumption. In this multivariate linear regression analyses, with a consumption increase of $250 \mathrm{~g} /$ week as an exposure variable, the adjusted relative differences were $-0.9 \mathrm{~mm} \mathrm{Hg}$ and $-0.8 \mathrm{~mm} \mathrm{Hg}$ for systolic and diastolic BP, respectively.

In multivariate linear regression analyses of a sample restricted to $\sim 80 \%$ of patients included within the hypertension criterion from the beginning, a significant inverse association between gazpacho consumption category (g/ day) and BP was observed. No selection bias as described above occurred in this case. Adjusted relative differences in systolic BP were $-2.3 \mathrm{~mm} \mathrm{Hg}(95 \% \mathrm{Cl}:-4.0,-0.7 ; P=0.006)$ for moderate consumption and $-2.5 \mathrm{~mm} \mathrm{Hg}(95 \% \mathrm{Cl}:-4.3$, 
Table 2 Daily intake of selected foods and nutrients according to gazpacho consumption category.

\begin{tabular}{|c|c|c|c|c|}
\hline & \multicolumn{4}{|c|}{ Categories of gazpacho consumption (g/day) ${ }^{a}$} \\
\hline & $\begin{array}{l}\text { No consumption }{ }^{\mathrm{b}} \\
(0 \mathrm{~g} / \mathrm{d})\end{array}$ & $\begin{array}{l}\text { Moderate } \\
\text { consumption } \\
(1-19 \mathrm{~g} / \mathrm{d})\end{array}$ & $\begin{array}{l}\text { High consumption } \\
(>20 \mathrm{~g} / \mathrm{d})\end{array}$ & $P^{c}$ \\
\hline No. of subjects & 1878 & 994 & 1090 & \\
\hline Gazpacho (g) & $0.0(0.0)$ & $9.3(0.0)$ & $49.0(39.3)$ & $<0.001$ \\
\hline Olive oil (g) & 41.82 (17.59) & $43.94(18.73)$ & 46.88 (18.99) & $<0.001$ \\
\hline Total nuts (g) & $9.63(14.19)$ & $9.20(12.02)$ & $11.14(14.71)$ & 0.002 \\
\hline Fruits (g) & 352.51 (189.05) & 354.09 (194.63) & $431.72(253.32)$ & $<0.001$ \\
\hline Vegetables (g) & 308.09 (145.99) & 348.79 (140.58) & $401.28(179.58)$ & $<0.001$ \\
\hline $\begin{array}{l}\text { Total fruits and } \\
\text { vegetables (g) }\end{array}$ & $660.60(260.04)$ & $702.89(265.34)$ & $832.99(357.84)$ & $<0.001$ \\
\hline Legumes (g) & $19.38(14.03)$ & $20.53(11.81)$ & 22.61 (13.19) & $<0.001$ \\
\hline Fish or seafood (g) & 93.63 (45.98) & $105.48(50.63)$ & $121.67(63.72)$ & $<0.001$ \\
\hline $\begin{array}{l}\text { Meat or meat } \\
\text { products }(\mathrm{g})\end{array}$ & $136.13(61.49)$ & $126.88(56.10)$ & $128.06(65.57)$ & $<0.001$ \\
\hline $\begin{array}{l}\text { Pastries, cakes } \\
\text { or sweets (g) }\end{array}$ & $27.10(35.21)$ & $24.58(33.21)$ & $24.96(30.77)$ & 0.09 \\
\hline Cereals (g) & 225.75 (110.77) & $223.08(100.74)$ & $211.38(106.72)$ & 0.002 \\
\hline $\begin{array}{l}\text { Milk and dairy } \\
\text { products }(\mathrm{mL})\end{array}$ & $384.14(226.50)$ & $384.49(210.87)$ & 416.35 (232.85) & $<0.001$ \\
\hline Wine $(m L)$ & $66.08(125.62)$ & $56.29(104.04)$ & $55.00(96.62)$ & 0.014 \\
\hline Coffee (mL) & $66.60(54.48)$ & $71.68(53.00)$ & $77.81(54.84)$ & $<0.001$ \\
\hline Tea $(\mathrm{mL})$ & $5.06(24.39)$ & $5.56(24.28)$ & $5.51(19.51)$ & 0.81 \\
\hline Chocolate (g) & $2.21(6.07)$ & $2.61(7.02)$ & $3.64(8.72)$ & $<0.001$ \\
\hline $\begin{array}{l}\text { Natural orange } \\
\text { juice }(\mathrm{mL})\end{array}$ & $19.86(54.86)$ & $24.49(56.28)$ & $33.48(62.46)$ & $<0.001$ \\
\hline Alcohol (g) & 9.09 (15.85) & $8.39(14.78)$ & $8.94(13.54)$ & 0.49 \\
\hline Fiber (g) & $24.42(8.51)$ & $25.50(8.58)$ & $27.33(10.45)$ & $<0.001$ \\
\hline Cholesterol (g) & $363.86(141.54)$ & $369.96(123.61)$ & 407.09 (159.61) & $<0.001$ \\
\hline Sodium (mg) & 2296.24 (941.47) & 2354.52 (829.53) & 2726.81 (993.17) & $<0.001$ \\
\hline Potassium (mg) & $4169.31(1036.38)$ & $4335.29(1019.65)$ & 4809.44 (1303.97) & $<0.001$ \\
\hline $\begin{array}{l}\text { Total polyphenol } \\
\text { intake }\left(\mathrm{mg} \mathrm{GAE}{ }^{\mathrm{d}}\right)\end{array}$ & $1126.87(518.20)$ & 1170.51 (521.57) & $1314.68(541.12)$ & $<0.001$ \\
\hline $\begin{array}{l}\text { 14-unit Mediterranean } \\
\text { diet score, mean (SD) }\end{array}$ & $8.62(1.92)$ & $8.99(1.92)$ & $9.26(1.85)$ & $<0.001$ \\
\hline Total energy, kcal/d & 2269.63 (618.89) & 2297.96 (574.59) & $2483.05(658.50)$ & $<0.001$ \\
\hline
\end{tabular}

$-0.8 ; P=0.005)$ for high consumption. The relative differences for diastolic BP were $-1.6 \mathrm{~mm} \mathrm{Hg}(95 \% \mathrm{Cl}:-2.5,-0.7$; $P=0.001)$ for moderate consumption and $-1.9 \mathrm{~mm} \mathrm{Hg}$ (95\% Cl: $-2.9,-0.9 ; P<0.001)$ for high consumption.

Logistic regression analysis revealed an inverse association between gazpacho consumption and the prevalence of hypertension (Table 4). When the analysis was adjusted for all possible confounders (model 3), the prevalence of hypertension among gazpacho consumption ( $250 \mathrm{~g} /$ week) was significantly reduced (OR $0.85,95 \% \mathrm{Cl}: 0.73,0.99 ; P=0.04$ ) compared to non-consumption; in addition, the prevalence of hypertension was significantly reduced $(\mathrm{OR}=0.73,95 \% \mathrm{Cl}$ : $0.55 ; 0.98)$ for high gazpacho consumption groups compared to the no-consumption group, but it was not significantly reduced when moderate gazpacho consumption group was compared with the no-consumption group.

\section{Discussion}

In this cross-sectional study of a large Spanish cohort of subjects at high cardiovascular risk, we observed an inverse association between gazpacho consumption, a ready-made Spanish cold vegetable soup rich in carotenoid, vitamin C and polyphenols, and the prevalence of hypertension. In addition, systolic and diastolic BP levels were inversely associated with gazpacho consumption categories and inversely associated with a consumption increase of $250 \mathrm{~g} /$ week, after adjustment for potential confounders, including total fruit and vegetable intake. As gazpacho is a mix of vegetables, the results confirm the benefit on BP of increased vegetable intake [3]. The inverse association between gazpacho consumption and BP was independent of total vegetable intake, suggesting synergy in reducing BP 
Table 3 Multivariate linear regression analyses (difference of means, $95 \% \mathrm{Cl}^{\mathrm{a}}$ ) of systolic and diastolic blood pressure according to categories of gazpacho consumption and changes associated with a consumption increase of $250 \mathrm{~g} /$ week (difference of means, $95 \% \mathrm{Cl}$ ).

\begin{tabular}{|c|c|c|c|c|c|c|c|c|c|c|c|}
\hline & \multicolumn{8}{|c|}{ Categories of gazpacho consumption (g/day) } & \multicolumn{3}{|l|}{$250 \mathrm{~g} /$ week } \\
\hline & \multicolumn{2}{|c|}{ No consumption ${ }^{\mathrm{b}}(0 \mathrm{~g} / \mathrm{d})$} & \multicolumn{2}{|c|}{$\begin{array}{l}\text { Moderate consumption } \\
(1-19 \mathrm{~g} / \mathrm{d})\end{array}$} & $P^{c}$ & \multicolumn{2}{|c|}{$\begin{array}{l}\text { High consumption } \\
(>20 \mathrm{~g} / \mathrm{d})\end{array}$} & $P^{c}$ & $\begin{array}{l}\text { Changes } \\
\text { associated } \\
\text { with } 250 \mathrm{~g} / \text { week }\end{array}$ & $\mathrm{Cl}$ & $P^{c}$ \\
\hline $\begin{array}{l}\text { Unadjusted mean } \\
\text { Relative differences }\end{array}$ & 150.3 & $149.4,151.2$ & 147.7 & $146.5,148.9$ & & 147.5 & $146.6,148.6$ & & 149.4 & $148.6,150.1$ & \\
\hline Age-, sex-, weight-adjusted & 0 & Referent & -2.1 & $-3.6,-0.6$ & 0.006 & -2.7 & $-4.2,-1.2$ & $<0.001$ & -1.0 & $-1.8,-0.2$ & 0.01 \\
\hline 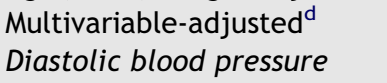 & 0 & Referent & -1.9 & $-3.4,-0.4$ & 0.01 & -2.6 & $-4.2,-1.0$ & 0.001 & -0.9 & $-1.8,-0.1$ & 0.03 \\
\hline $\begin{array}{l}\text { Unadjusted mean } \\
\text { Relative differences }\end{array}$ & 83.6 & $83.2,84.1$ & 82.4 & $81.7,83.1$ & & 82.1 & $81.4,82.7$ & & 83.2 & $82.8,83.6$ & \\
\hline $\begin{array}{l}\text { Age-, sex-, weight-adjusted } \\
\text { Multivariable-adjusted }^{\text {d }}\end{array}$ & $\begin{array}{l}0 \\
0\end{array}$ & $\begin{array}{l}\text { Referent } \\
\text { Referent }\end{array}$ & $\begin{array}{l}-1.5 \\
-1.5\end{array}$ & $\begin{array}{l}-2.3,-0.7 \\
-2.3,-0.6\end{array}$ & $\begin{array}{l}<0.001 \\
<0.001\end{array}$ & $\begin{array}{l}-2.0 \\
-1.9\end{array}$ & $\begin{array}{l}-2.8,-1.2 \\
-2.8,-1.1\end{array}$ & $\begin{array}{l}<0.001 \\
<0.001\end{array}$ & $\begin{array}{l}-0.9 \\
-0.8\end{array}$ & $\begin{array}{l}-1.3,-0.5 \\
-1.3,-0.4\end{array}$ & $\begin{array}{l}<0.001 \\
<0.001\end{array}$ \\
\hline $\begin{array}{l}\text { a Confidence Intervals. } \\
\text { b Reference category. } \\
\text { c } P \text { : two-sided test of signific } \\
\text { d Adjusted for sex, age, wei } \\
\text { hypertensive drugs, statins or o } \\
\text { taken in the last month, dyslipi }\end{array}$ & $\begin{array}{l}\text { tce. } \\
\text { t, smo } \\
\text { ler hyp }\end{array}$ & atus, energy e & $\begin{array}{l}\text { diture } \\
\text { ral hy }\end{array}$ & $\begin{array}{l}\text { hysical activ } \\
\text { cemic drugs }\end{array}$ & $\begin{array}{l}\text { lucatio } \\
\text { n or ot }\end{array}$ & eve & edication in & $\begin{array}{l}\text { (anti- } \\
\text { ements } \\
\text { al fruit }\end{array}$ & & & \\
\hline
\end{tabular}


Table 4 Multivariate adjusted odds ratios $\left(95 \% \mathrm{Cl}^{\mathrm{a}}\right)$ for hypertension by gazpacho consumption expressed as $250 \mathrm{~g} /$ week and as categories of gazpacho consumption (moderate and high consumption groups compared to the no-consumption group).

\begin{tabular}{|c|c|c|c|c|}
\hline \multirow[b]{2}{*}{ Models ${ }^{c}$} & \multirow{2}{*}{$\begin{array}{l}\mathrm{OR}^{\mathrm{b}} \\
\text { For } 250 \mathrm{~g} / \text { week }\end{array}$} & \multicolumn{3}{|c|}{$95 \% \mathrm{Cl}$ for $\mathrm{OR}$} \\
\hline & & Lower & Upper & $P^{\mathrm{d}}$ \\
\hline Model 1 & 0.93 & 0.84 & 1.02 & 0.10 \\
\hline lodel 2 & 0.92 & 0.84 & 1.01 & 0.09 \\
\hline Model 3 & 0.85 & 0.73 & .99 & 0.04 \\
\hline \multicolumn{5}{|c|}{ Moderate compared with no-consumption } \\
\hline Model 1 & 1.01 & 0.83 & 1.24 & 0.91 \\
\hline Model 2 & 0.99 & 0.81 & 1.23 & 0.99 \\
\hline Model 3 & 0.93 & 0.71 & 1.23 & 0.62 \\
\hline \multicolumn{5}{|c|}{ High compared with no-consumption } \\
\hline Model 1 & 0.89 & 0.73 & 1.08 & 0.2 \\
\hline Model 2 & 0.87 & 0.71 & .06 & 0.16 \\
\hline Model 3 & 0.73 & 0.55 & 0.98 & 0.03 \\
\hline \multicolumn{5}{|c|}{$\begin{array}{l}\text { a Confidence Intervals. } \\
\text { b OR: Odds ratio. } \\
\text { c Model } 1 \text {, unadjusted; Model } 2 \text { was adjusted for sex, age and } \\
\text { weight; Model } 3 \text { adjusted as in Model } 2 \text { plus for smoking status, } \\
\text { physical activity, educational level, energy expenditure in } \\
\text { physical activity and, medication intake (antihypertensive } \\
\text { drugs, statins or other hypolipidemic drugs, insulin, oral hypo- } \\
\text { glycemic drugs, aspirin or other antiplatelet drug), supplements } \\
\text { taken in the last month, dyslipidemia, family history of coro- } \\
\text { nary heart disease, diabetes, as well as for intake of carbohy- } \\
\text { drates, total fruit and vegetables, alcohol, sodium, potassium, } \\
\text { 14-unit Mediterranean diet score and total energy intake. } \\
\text { d Two-sided test of significance. }\end{array}$} \\
\hline
\end{tabular}

among bioactive compounds in a recipe that includes a complex mixture of plant foods, with olive oil that increase bioavailability of phenolic compounds [21].

Hypertension is an unequivocal risk factor for cardiovascular morbidity and mortality, and is the main risk factor for stroke in both men and women. The estimated total number of adults with hypertension in 2000 was 972 million (957-987 million) and is predicted to increase by about $60 \%$ to a total of 1.56 billion in 2025 [22].

The first step in the prevention and management of hypertension is to follow a plant-based diet such as the DASH or Mediterranean diets [3], which are considered rich sources of phytochemicals and are inversely associated with high BP in epidemiologic studies [4].

Recently, "gazpacho" has acquired importance in Western societies due to the increasing interest in the Mediterranean diet. A serving of "gazpacho" (250 g) typically contributes $120 \mathrm{kcal}$, which comes mainly from olive oil. The mixture of all the ingredients contributes to the intake of carbohydrates $(40 \mathrm{~g} / \mathrm{kg})$ and fibers $(12 \mathrm{~g} / \mathrm{kg})$. Besides, gazpacho contains protein $(10 \mathrm{~g} / \mathrm{kg})$, and sizeable amounts of vitamins and minerals. The sodium content in "gazpacho" is high compared to that of plant foods due to addition of salt in the recipe, the mean value founded in "gazpacho" is $1,073 \mathrm{mg} / \mathrm{kg}$ [23].

Recent research has shown that the raw ingredients of gazpacho exert potentially valuable antihypertensive effects. Thus, a diet rich in fruit and vegetables may help prevent BP increases and reduce elevated BP levels [24]. In the Mediterranean cohort of the Seguimiento Universidad de Navarra (SUN) study [10], the prevalence of hypertension was inversely associated with fruit and vegetable consumption. In a study of 983 Indian adults, increasing fruit and vegetable intake was inversely associated with systolic BP [25].

Tomato is a critical ingredient of gazpacho, and tomato consumption has been associated with reduced cardiovascular risk factors. Tomato extract supplementation was associated with a clinically significant reduction of systolic and diastolic BP in hypertensive patients [15]. Garlic extract has also been associated with reduced systolic BP in patients with hypertension [16]. Mediterranean diets enriched in olive oil have been associated with reduced systolic and diastolic BP in subjects with overweight [6], or increased cardiovascular risk [7]. Finally, a significant decrease in systolic BP was observed in 24 hypertensive patients after 1-wk treatment with a daily dose of 4 capsules of an onion-olive oil maceration product [26]. Thus, the main ingredients of gazpacho have been associated with reduced BP in epidemiological and clinical studies.

High salt intake harms the cardiovascular system by raising $\mathrm{BP}$ and might be directly responsible for increasing left ventricular mass, as suggested in clinical and experimental studies $[27,28]$. Consistent with this, there is also evidence that high salt intake aggravates and, inversely, dietary salt restriction prevents (or at least mitigates) left ventricular hypertrophy in patients with essential hypertension. Some clinical trials have shown that reducing the sodium chloride content of typical diets in the United States or northern Europe lowers BP, and guidelines recommend reducing the daily dietary sodium intake to $100 \mathrm{mmol}$ (equivalent to $2.3 \mathrm{~g}$ of sodium or $5.8 \mathrm{~g}$ of sodium chloride) or less.

The low-sodium DASH diet produced greater reductions in systolic and diastolic BP than either the DASH diet alone or a reduction in sodium alone, compared with the highsodium control diet [5]. In a meta-regression analysis of randomized trials [8], a median $-77 \mathrm{mmol} / 24 \mathrm{~h}$ sodium reduction was associated with a change of $-2.54 \mathrm{~mm} \mathrm{Hg}$ and $-1.96 \mathrm{~mm} \mathrm{Hg}$ in systolic and diastolic BP, respectively.

In spite of the salt content of homemade and commercial gazpachos, its consumption in the current study was associated with a significant reduction in systolic and diastolic BP. Presumably, the sodium content of gazpacho is counteracted by the high levels of potentially antihypertensive minerals, such as potassium, magnesium, and calcium [3], contained in its main components. Part of the anti-hypertensive effect of gazpacho may also be attributed to its phenolic content. The main sources of polyphenols are fruit, vegetables and beverages such as wine, tea and also gazpacho. By example, the total phenol content of 12 tested commercial Mediterranean gazpachos ranged between 11.54 and $17.52 \mathrm{mg} / 100 \mathrm{~g}$ [29].

Urinary polyphenol excretion, a biomarker of total polyphenol intake, was directly related to fruit and vegetable intake and inversely associated with BP levels and the prevalence of hypertension in another cross-sectional study of the PREDIMED trial [24]. Thus, clinical and epidemiological evidence supports the antihypertensive effect of 
foods and diets rich in polyphenols. Because greater gazpacho intake means higher polyphenol consumption, we suggest that the observed inverse association between gazpacho consumption categories and BP relates in part to a beneficial effect of polyphenols intake on BP.

Our study has limitations. First, given that our study subjects were elderly and at high risk of cardiovascular disease, the results may not be generalized to other populations. However, since most study subjects were hypertensive, our findings confirm the usefulness of polyphenol-rich diets in the management of hypertension. Another limitation of our study is its cross-sectional nature, which does not allow establishing definite causal relationships. Nevertheless, reverse causality bias seems improbable, since gazpacho contains salt and its regular use is not recommended to patients with hypertension. Clearly, clinical trials aimed at exploring the effects of gazpacho consumption on BP are warranted.

In conclusion, in this cross-sectional study within the framework of the PREDIMED trial in a high-risk Mediterranean population, gazpacho consumption was inversely associated with BP levels and prevalence of hypertension. However, the observation that systolic and diastolic BP decrease with increasing gazpacho consumption should be confirmed in randomized clinical trials. Further studies are also needed to clarify whether functional compounds present in gazpacho, differently contribute to this apparent beneficial health effect, counteracting the possible deleterious effect of the salt that it contains.

\section{Acknowledgments}

We thank the participants in the PREDIMED study for their valuable cooperation. This work was supported by CICYT [AGL2010-22319-C03] and RETICS[RD06/0045] from MICINN. None of the funding sources played a role in the design, collection, analysis and interpretation of data, in the writing of the report or in the decision to submit the paper for publication.

\section{Appendix 1. Other PREDIMED Investigators}

Nutrition and Food Science Department, XaRTA, INSA. Pharmacy School, University of Barcelona, Barcelona, Spain: Anna Tresserra-Rimbau, BS; Miriam Martínez-Huélamo, MD; Carmen Lopéz-Sabater, PhD and Ana Isabel Castellote, PhD. Hospital Clinic, Institut d'Investigacions Biomèdiques August Pi Sunyer, Barcelona, Spain: Palmira Valderas-Martínez, MD; Rosa Casas, BS; Gemma ChivaBlanch, MD; Mireia Urpi-Sarda, PhD and Concha Viñas, RD. University of Navarra, Primary Care Division, Pamplona, Spain: Estefania Toledo, MD, PhD; Pilar Buil-Cosiales, MD, and Javier Diez-Espino, MD; Amelia Marti and J. Alfredo Martínez. University of Valencia, Valencia, Spain: Olga Portolés, PhD; José Vicente Sorlí, MD. University Rovira i Virgili, Reus (Tarragona), Spain: Mónica Bulló, PhD; Josep Basora, MD; Nancy Babio, PhD. Nutrition and Lipids Metabolism. Instituto de la Grasa, Consejo Superior de Investigaciones Científicas, Sevilla, Spain: Maria Garcia and Emilio Montero. Municipal Institute for Medical Research,
Barcelona, Spain: Montserrat Fitó, PhD; Jaime Marrugat, MD, PhD; Roberto Elosúa, MD, PhD. University of Málaga, Málaga, Spain: Juan José Sánchez-Luque, MD, PhD; Virginia Velasco-García, MD. University Institute for Health Sciences Investigation, Palma de Mallorca, Spain: Fernando Rigo, MD; Guillem Frontera, MD. Primary Care Division, Catalan Institute of Health, Barcelona, Spain: Carmen Cabezas, MD. Hospital Txagorritxu,Vitoria, Spain: E. Sanz MD. Hospital Universitario Virgen del Rocío, Sevilla, Spain: Adoración Nieto, MD, PhD. Department of Family Medicine, Primary Care Division of Sevilla, San Pablo Health Center, Sevilla: José Manuel Santos, MD, PhD; Pablo Iglesias, MD, PhD; Manuel Ortega, MD, PhD.

\section{References}

[1] Lawes CM, Vander HS, Rodgers A. Global burden of bloodpressure-related disease, 2001. Lancet 2008;371(9623): 1513-8.

[2] Dickinson HO, Mason JM, Nicolson DJ, Campbell F, Beyer FR, Cook JV, et al. Lifestyle interventions to reduce raised blood pressure: a systematic review of randomized controlled trials. J Hypertens 2006;24(2):215-33.

[3] Appel LJ, Brands MW, Daniels SR, Karanja N, Elmer PJ, Sacks FM. Dietary approaches to prevent and treat hypertension: a scientific statement from the American Heart Association. Hypertension 2006;47(2):296-308.

[4] Appel LJ, Moore TJ, Obarzanek E, Vollmer WM, Svetkey LP, Sacks FM, et al. A clinical trial of the effects of dietary patterns on blood pressure. N Engl J Med 1997;336(16):1117-24.

[5] Sacks FM, Svetkey LP, Vollmer WM, Appel LJ, Bray GA, Harsha $D$, et al. Effects on blood pressure of reduced dietary sodium and the Dietary Approaches to Stop Hypertension (DASH) diet. DASH-Sodium Collaborative Research Group. N Engl J Med 2001;344(1):3-10.

[6] Esposito K, Marfella R, Ciotola M, Di PC, Giugliano F, Giugliano $G$, et al. Effect of a Mediterranean-style diet on endothelial dysfunction and markers of vascular inflammation in the metabolic syndrome: a randomized trial. JAMA 2004; 292(12):1440-6.

[7] Estruch R, Martinez-Gonzalez MA, Corella D, Salas-Salvado J, Ruiz-Gutierrez V, Covas MI, et al. Effects of a Mediterraneanstyle diet on cardiovascular risk factors: a randomized trial. Ann Intern Med 2006;145(1):1-11.

[8] Geleijnse JM, Kok FJ, Grobbee DE. Blood pressure response to changes in sodium and potassium intake: a metaregression analysis of randomised trials. J Hum Hypertens 2003;17(7): 471-80.

[9] Sofi F, Abbate R, Gensini GF, Casini A. Accruing evidence on benefits of adherence to the Mediterranean diet on health: an updated systematic review and meta-analysis. Am J Clin Nutr 2010;92(5):1189-96.

[10] Alonso A, de la Fuente C, Martin-Arnau AM, de Irala J, Martinez JA, Martinez-Gonzalez MA. Fruit and vegetable consumption is inversely associated with blood pressure in a Mediterranean population with a high vegetable-fat intake: the Seguimiento Universidad de Navarra (SUN) Study. Br J Nutr 2004;92(2):311-9.

[11] Mancia G, De BG, Dominiczak A, Cifkova R, Fagard R, Germano G, et al. 2007 guidelines for the management of arterial hypertension: the task force for the management of arterial hypertension of the European Society of Hypertension (ESH) and of the European Society of Cardiology (ESC). J Hypertens 2007;25(6):1105-87.

[12] Engberink MF, Hendriksen MA, Schouten EG, van Rooij FJ, Hofman A, Witteman JC, et al. Inverse association between 
dairy intake and hypertension: the Rotterdam Study. Am J Clin Nutr 2009;89(6):1877-83.

[13] Vallverdú-Queralt A, Arranz S, Casals-Ribes I, LamuelaRaventos RM. Stability of the phenolic and carotenoid profile of gazpachos during storage. J Agric Food Chem 2012;60(8): 1981-8.

[14] Vallverdú-Queralt A, Martinez-Huelamo M, Arranz-Martinez S, Miralles E, Lamuela-Raventos RM. Differences in the carotenoid content of ketchups and gazpachos through HPLC/ESI(Li(+) )-MS/MS correlated with their antioxidant capacity. J Sci Food Agric 2012;92(10):2043-9.

[15] Paran E, Novack V, Engelhard YN, Hazan-Halevy I. The effects of natural antioxidants from tomato extract in treated but uncontrolled hypertensive patients. Cardiovasc Drugs Ther 2009;23(2):145-51.

[16] Ried K, Frank OR, Stocks NP. Aged garlic extract lowers blood pressure in patients with treated but uncontrolled hypertension: a randomised controlled trial. Maturitas 2010;67(2): 144-50.

[17] Bondia-Pons I, Schroder H, Covas MI, Castellote Al, Kaikkonen J, Poulsen HE, et al. Moderate consumption of olive oil by healthy European men reduces systolic blood pressure in non-Mediterranean participants. J Nutr 2007;137(1):84-7.

[18] Martinez-Gonzalez MA, Corella D, Salas-Salvado J, Ros E, Covas MI, Fiol M, et al. Cohort Profile: design and methods of the PREDIMED study. Int J Epidemiol 2010.

[19] Nigg CR, Burbank PM, Padula C, Dufresne R, Rossi JS, Velicer WF, et al. Stages of change across ten health risk behaviors for older adults. Gerontologist 1999;39(4):473-82.

[20] Iglesias-Bonilla P, Mayoral-Sánchez E, Lapetra-Peralta J, Iborra-Oquendo M, Villalba-Alcalá F, Cayuela-Domínguez A. Validación de dos sistemas de automedida de presión arterial, modelos OMRON HEM 705 CP y OMRON MI (HEM 422C2-E). Aten Primaria 2002;30(1):22-8.

[21] Tulipani S, Martinez Huelamo M, Rotches-Ribalta M, Estruch R, Ferrer EE, Andres-Lacueva $C$, et al. Oil matrix effects on plasma exposure and urinary excretion of phenolic compounds from tomato sauces: evidence from a human pilot study. Food Chem 2012;130(3):581-90.

[22] Kearney PM, Whelton M, Reynolds K, Whelton PK, He J. Worldwide prevalence of hypertension: a systematic review. $J$ Hypertens 2004;22(1):11-9.

[23] Verde Mendez CM, Rodriguez Rodriguez EM, Diaz RC, Matallana Gonzalez MC, Torija Isasa ME. Comparison of the mineral and trace element concentrations between 'gazpacho' and the vegetables used in its elaboration. Int J Food Sci Nutr 2008;59(7-8):660-70.

[24] Medina-Remón A, Zamora-Ros R, Rotchés-Ribalta M, AndresLacueva C, Martinez-Gonzalez MA, Covas MI, et al. Total polyphenol excretion and blood pressure in subjects at high cardiovascular risk. Nutr Metab Cardiovasc Dis 2011;21(5): 323-31.

[25] Radhika G, Sudha V, Mohan Sathya R, Ganesan A, Mohan V. Association of fruit and vegetable intake with cardiovascular risk factors in urban south Indians. Br J Nutr 2008;99(02): 398-405.

[26] Mayer B, Kalus U, Grigorov A, Pindur G, Jung F, Radtke H, et al. Effects of an onion-olive oil maceration product containing essential ingredients of the Mediterranean diet on blood pressure and blood fluidity. Arzneimittelforschung 2001; 51(2):104-11.

[27] de Simone G, Devereux RB, Camargo MJ, Wallerson DC, Laragh JH. Influence of sodium intake on in vivo left ventricular anatomy in experimental renovascular hypertension. Am J Physiol 1993;264(6 Pt 2):H2103-10.

[28] Schmieder RE, Langenfeld MR, Friedrich A, Schobel HP, Gatzka CD, Weihprecht $H$. Angiotensin II related to sodium excretion modulates left ventricular structure in human essential hypertension. Circulation 1996;94(6): 1304-9.

[29] Vallverdú-Queralt A, Medina-Remón A, Estruch R, LamuelaRaventos RM. Light gazpachos contain higher phytochemical levels than conventional gazpachos. Food Sci Technol Int 2012;47(1):154-60. 